\title{
AVALIAÇÃO MOLECULAR DAS VIAS IMUNOLÓGICAS DE SINALIZAÇÃO CELULAR EM Aedes aegypti INFECTADO COM Metarhizium anisopliae
}

\author{
Sara Z. Cabral ${ }^{1}$ \\ Anderson Ribeiro ${ }^{2}$ \\ Adriano Rodrigues de Paula ${ }^{3}$ \\ Richard lan Samuels ${ }^{4}$ \\ Rodrigo N. da Fonseca ${ }^{5}$ \\ Simone A. Gomes ${ }^{6}$ \\ Flávia B. Mury ${ }^{7}$
}

Resumo: Recentes trabalhos mostraram que fêmeas de Aedes aegypti alimentadas com sangue foram menos suscetíveis ao fungo Metarhizum anisopliae, comparado com fêmeas alimentadas com sacarose. Desde então estudos tem sido feitos investigando o porquê desses resultados. No presente trabalho foi avaliado a expressão dos genes relacionados às vias Toll, Immune Deficiency (IMD) e Janus Quinase (JAKSTAT) de A. aegypti alimentadas com sangue ou sacarose. As fêmeas de A. aegypti foram infectadas com M. anisopliae e 48 horas depois foram dissecadas para obtenção do corpo gorduroso (CG) e epitélio intestinal (EI). Realizou-se extração de RNA total, obtenção de CDNA e análise por PCR em tempo real. Nossos resultados mostraram que ocorreu uma modulação positiva na expressão dos genes Relish $1 \mathrm{~A}$, Cactus e STAT no epitélio intestinal e corpo gorduroso em fêmeas alimentadas com sacarose e infectadas com fungo.

Palavras-chave: Aedes aegypti; Sistema imune; Metarhizium anisopliae.

\footnotetext{
1 Universidade Federal do Rio de Janeiro - Núcleo de Ecologia e Desenvolvimento Socioambiental de Macaé Laboratório Integrado de Bioquímica Hatisaburo Masuda, Av. São Jose do Barreto, 724, Macaé-RJ, Brasil. E-mail: sara_z_c@hotmail.com

2 Universidade Estadual do Norte Fluminense - Centro de Ciências e Tecnologias Agropecuárias - Laboratório de Entomologia e Fitopatologia, Av. Alberto Lamego, 2000, Campos dos Goytacazes-RJ, Brasil. E-mail: anderson.ribeirorj@yahoo.com.br.

${ }^{3}$ Universidade Estadual do Norte Fluminense - Centro de Ciências e Tecnologias Agropecuárias - Laboratório de Entomologia e Fitopatologia, Av. Alberto Lamego, 2000, Campos dos Goytacazes-RJ, Brasil. E-mail: biodepaula@yahoo.com.br.

${ }^{4}$ Universidade Estadual do Norte Fluminense - Centro de Ciências e Tecnologias Agropecuárias - Laboratório de Entomologia e Fitopatologia, Av. Alberto Lamego, 2000, Campos dos Goytacazes-RJ, Brasil. E-mail: richard@uenf.br

5 Universidade Federal do Rio de Janeiro - Núcleo de Ecologia e Desenvolvimento Socioambiental de Macaé Laboratório Integrado de Ciências Morfofuncionais, Av. São Jose do Barreto, 724, Macaé-RJ, Brasil. E-mail: rodrigo.nunes.da.fonseca@gmail.com

6 Universidade Federal do Rio de Janeiro - Núcleo de Ecologia e Desenvolvimento Socioambiental de Macaé Laboratório Integrado de Bioquímica Hatisaburo Masuda, Av. São Jose do Barreto, 724, Macaé-RJ, Brasil. E-mail: simoneaz.gomes@yahoo.com.br

7 Universidade Federal do Rio de Janeiro - Núcleo de Ecologia e Desenvolvimento Socioambiental de Macaé Laboratório Integrado de Bioquímica Hatisaburo Masuda, Av. São Jose do Barreto, 724, Macaé-RJ, Brasil. E-mail: fbmury@macae.ufrj.br
} 